\title{
Reconstruindo alguns modelos sobre luz e visão da história da ciência
}

\author{
Lisbeth Lorena Alvarado Guzmán*, Roberto Nardi**
}

\section{Resumo}

Ao longo da história se há tecido concepções sobre a luz e a visão que se evidenciam em campos tão diversos como a física, a teologia, a psicologia, a biologia, entre outros. Isto têm implicado no desenvolvimento de tecnologias com diversas aplicações, ao mesmo tempo, em que alcançam novos entendimentos e outros fenômenos surgiram. O objetivo fundamental deste artigo é fazer um tour por alguns modelos de luz e visão que foram coletados da história da óptica, dando atenção especial a refração. Da mesma forma, traz uma breve discussão sobre a tecnologia e suas relações com a ciência por meio da análise do papel da câmera escura como análogo ao olho, expandindo a compreensão do mecanismo da visão e mostrando uma gama de aplicações provenientes de campos tão diversos como a pintura. Conclui-se que a história da óptica é extensa e repleta de detalhes que nos mostram como a ciência se desenvolve através de controvérsias, da comunicação entre cientistas e da necessidade de explicar, prever e criar fenômenos. Longe de pretender ser exaustivo na apresentação dos modelos, o que se evidencia é a demarcação dos fenômenos e a estabilização dos fatos que dão origem a um modelo teórico. Por fim, são sugeridas algumas contribuições para os professores a partir de uma perspectiva da natureza da ciência e da tecnologia que podem ser consideradas em sala de aula.

Palavras-chave: História da óptica, Modelos de Visão, Refração, Câmera Escura, Ensino de Óptica.

\footnotetext{
- Doutoranda em Educação para a Ciência - Programa de Pós-Graduação em Educação para a Ciência da Universidade Estadual Paulista “Júlio Mesquita Filho" (UNESP). E-mail: lisbeth.alvaradofm@gmail.com. ORCID: http:// orcid.org/0000-0003-0407-7921
}

* Doutor em Educação pela Universidade de São Paulo, (USP). Docente do Programa de Pós-Graduação em Educação para a Ciência da Universidade Estadual Paulista "Júlio Mesquita Filho" (UNESP). E-mail: rnardi@ unesp.br. ORCID: http://orcid.org/0000-0002-5018-3621 


\section{Introdução}

Lembrando a introdução da Estrutura das revoluções científicas (1962), intitulada "Um papel para a história", Kuhn menciona: "[...] Gradualmente, e muitas vezes sem perceber completamente que estão fazendo isso, os historiadores da ciência começaram a fazer novos tipos de perguntas e traçar linhas diferentes e muitas vezes dificilmente cumulativas de desenvolvimento científico" (KUHN, 1962, p. 104). Sob tal contexto, ao refletir sobre o papel da história na formação de professores de Física e na docência no ensino superior, torna-se necessário repensar sobre novas abordagens da história da ciência que possibilitem modificações no imaginário dos docentes e futuros professores acerca da construção e estabelecimento dos conhecimentos científicos e extrair contribuições para gerar novas formas de ensino. Sendo assim, é importante ressaltar que existem diferentes linhas sobre o desenvolvimento científico que se sobrepõem, divergem, convergem e se cruzam, mas como Kuhn mencionou, elas raramente são cumulativas.

Nesse sentido, a óptica é um dos ramos da física mais antigos e mais estudados. Isso pode estar relacionado ao caráter privilegiado da visão que nos fornece informações sobre o mundo exterior, distanciando-nos e afastando-nos dos perigos. Segundo Lindberg (1992, p. 152), "a luz é uma das entidades mais importantes e agradáveis neste mundo que não é apenas o instrumento da visão, mas também está conectado, na forma de luz solar, ao calor e à vida". Ao longo da história, foram geradas concepções sobre a visão e luz que envolveu contribuições de diversos campos como a física, a astronomia, a matemática, a teologia, a psicologia, a anatomia, a arte, entre outros. Isso mostra que a luz tem um caráter vital na forma como conhecemos e interagimos com o mundo, portanto compreender seu funcionamento e "dominá-la" tem implicado no desenvolvimento de fenômenos nunca vistos antes e tecnologias com aplicações em campos tão diversos como a medicina, a guerra, a tecnologia e nossa cotidianidade.

As seções que se seguem não pretendem ser um estudo exaustivo da óptica desde os gregos até o Newton, pelo contrário, procura estabelecer relações entre os diferentes modelos de visão e luz, os fenômenos associados à refração e alguns instrumentos que têm o olho e sua relação com a luz como analogia. 


\section{Modelos teóricos em física e didática das ciências}

As reflexões meta-científicas associadas à história, filosofia e sociologia da ciência encontraram uma base poderosa em modelos teóricos de uma perspectiva semanticista. A indagação sobre os produtos, leis, processos, sistemas e comunidades da ciência deixa de ser associada à sua forma para focar nos significados e sentidos que eles possuem, ou seja, para uma análise semântica (ARIZA; ADÚRIZ BRAVO, 2012). Essa ênfase também tem estado presente nos últimos anos na Didática das Ciências, gerando contribuições na imagem da natureza da ciência e dos conteúdos escolares.

Diante dessa importância, cabe perguntar o que é um modelo? A noção de modelo desde sua gênese é polissêmica e problemática, sendo abordada em campos como a matemática e gerando diferentes linhas e formas de compreender sua relação com as teorias. Dentro destas linhas, na concepção semanticista, está o trabalho do filósofo Ronald Giere $(1992 ; 1999)$ que usa a expressão "modelo cognitivo da ciência", e considera que os modelos têm um caráter mediador e representacional, situando-se entre as teorias e o mundo. No mesmo sentido, outra definição possível é: "os modelos são representações parciais e idealizadas do mundo (MOULINES; 2011) que nos ajudam a raciocinar sobre os fenômenos (cf. Grandy; Duschl 2007), constituindo uma parte essencial da identidade das teorias (ARIZA; ADÚRIZ BRAVO, 2012, p. 28)". Essa última definição destaca a parcialidade e a idealização da representação, bem como as duas características mencionadas por Giere: o caráter representacional e mediador dos modelos. A primeira é essencial para entender que o modelo não é realidade, embora dependa disso. A segunda característica redefine a teoria científica, visto que agora é concebida como uma família de modelos. Em ambos os casos, a semelhança que o modelo deve encontrar com o mundo real e as teorias faz com que tenham um "pé" na teoria e outro no "mundo" e nos afasta de posições que dão grande peso à teorização ou à experimentação no ensino de ciências.

Segundo Adúriz-Bravo e Morales (2002) citando a Duschl (1997), é possível identificar dois níveis de representação que são mediados por símbolos e significados que lhes atribuímos. O primeiro nível, denominado sistema físico (ADURIZ-BRAVO; MORALES, 2002), é uma representação de primeira ordem que estrutura o mundo dos fenômenos, transformando (organizando) os dados em evidência, estabelecendo um padrão e, portanto, pressupõe uma intervenção do homem para organizar sua 
realidade e torná-la mais compreensível. O segundo nível de representação inclui teorias sobre funções, propriedades e relacionamentos. Assim, fenômenos e conceitos aparecem vinculados à relação: teoria científica-modelo científico-mundo real, uma vez que, se espera que os primeiros sejam organizados em modelos para dar conta de um conjunto de fenômenos e/ou experiências no mundo que, por sua vez, geram conceitos e mostram a função semiótica da representação, ou seja, o papel da linguagem na significação e intervenção no mundo. A seguir, é apresentado um esquema retomado por Hernández Silva e Izquierdo (2017), no qual se exemplifica a relação entre a teoria científica- modelo científico-mundo real.

Figura 1: Modelo como conexão entre Teoria e Mundo, baseado em Giere (1999).

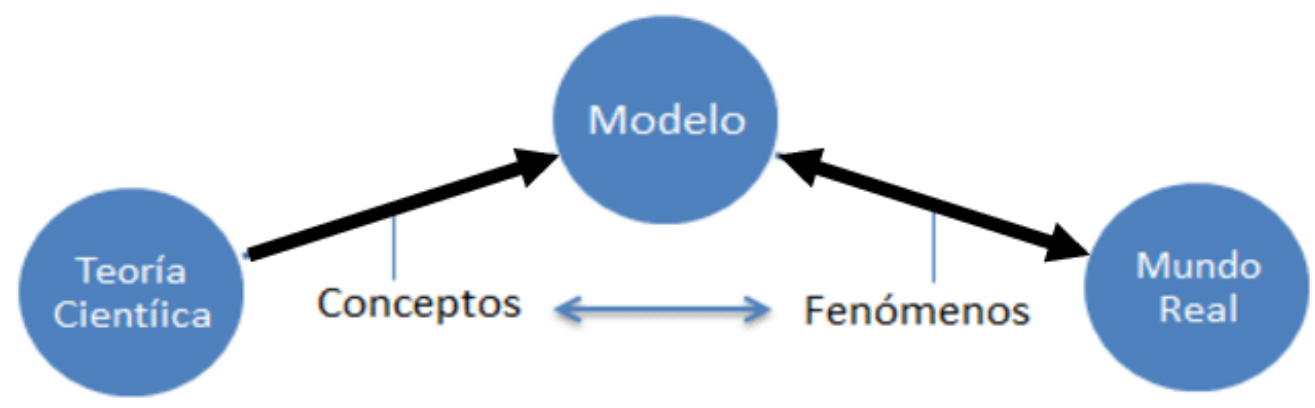

Fonte: HERNÁNDEZ SILVA; IZQUIERDO, 2017, p. 3882

A seguir, exploraremos diferentes modelos de visão com ênfase no reconhecimento dos fenômenos, teorias e elementos dos modelos que deram origem à forma como hoje concebemos a óptica e às explicações sobre a visão e a luz.

\section{Dos modelos de visão aos modelos de luz}

Os dois modelos físicos atuais que agrupam uma ampla gama de fenômenos associados à entidade física chamada luz são: corpuscular e ondulatório. Para se chegar à síntese de como se apresentam esses dois modelos, percorreu-se um longo caminho que possivelmente iniciou-se na Grécia antiga com as teorizações sobre o cosmos e o homem de alguns filósofos gregos. Assim, este será o nosso ponto de partida pois nessa época tornaram-se conhecidos vários fenômenos associados à 
luz e que, consequentemente, deram origem às teorias sobre a visão e a natureza da luz. No entanto, é relevante ressaltar que existem diferenças entre os modelos de visão e de luz, uma vez que o primeiro requer a intervenção de outras áreas do conhecimento como a anatomia, a neurologia, a física e a psicologia, entre outras.

\section{A natureza da luz na Grécia antiga}

Um dos historiadores que se encarregou de compilar as teorias sobre a luz e, em particular, o trabalho sobre refração foi Michel Authier (1989) que no texto "Refração e esquecimento cartesiano" faz uma análise histórica dos diferentes modelos de visão que surgiram ao longo da história desde os gregos e a refração como um fenômeno particular que conectava a natureza com o laboratório.

Voltando à ideia sobre modelos científicos, já foi mencionado que teorias e modelos respondem por uma porção da realidade ou do mundo, portanto, para compreender todos os elementos de um modelo, é necessário revelar a família de fatos que são agrupados sob o nome de refração. Assim, o próprio Kepler citado por Authier (1989, p. 287) caracteriza os seguintes fatos:

"Auroras com dedos rosados”, crepúsculos roxos, halos, glórias, múltiplos sóis e
arco-íris que encantaram os poetas. Estrelas visíveis antes do tempo programado,
desvios anormais das estrelas ou luas coloridas que por séculos surpreenderam os
astrônomos. Oásis, palmeiras, cidades maravilhosas surgiram nas dunas; costas,
faróis e navios visíveis de longa distância quando o tempo está quente, fenômenos
há muito conhecidos por nômades e marinheiros.

Os fatos que o Kepler enumera são diversos e pode-se dizer que são cotidianos para a época e fazem parte de diferentes domínios como astronomia, com os desvios anormais das estrelas, o arco-íris e os fenômenos conhecidos pelos marinheiros. Essa gama de fatos se estabilizou (FLECK et al., 1986) até a constituição de uma teoria que reunia uma pluralidade de entidades e modelos. Não sem antes passar por várias controvérsias.

Os atomistas, que aparecem na Grécia antiga no século V a.C, com expoentes como Leucipo, Demócrito e Lucrécio, consideraram que os objetos são aqueles que manifestam sua presença por meio de uma entidade chamada eidola, que é uma espécie de sombra ou simulacro que penetra na retina e gera uma impressão de formas e cores. De acordo com Lucrécio, citado por Authier (1989) 
Por isso é necessário que se confessem // as emissões das simulações // que ferem muitos olhos e produzem // visão [...] Temos tanta certeza // que todos os corpos enviam emissões // de si próprios continuamente / / que rodam por todo o lado sem parar [...] e a imagem faz-nos ver // a distância entre as coisas porque ao sair impulsiona e sopra o ar // que faz a mediação entre a imagem e os olhos (Tito Lucrécio Caro, Sobre a natureza das coisas, Trad. Of Abbe Marchena, Espasa-Calpe, Col. Austral 1969 citado por AUTHIER, 1989, p. 289).

Abaixo se mostra a Figura 2 que representa a eidola que vai do objeto ao olho.

Figura 2: Representação modelo da visão atomista

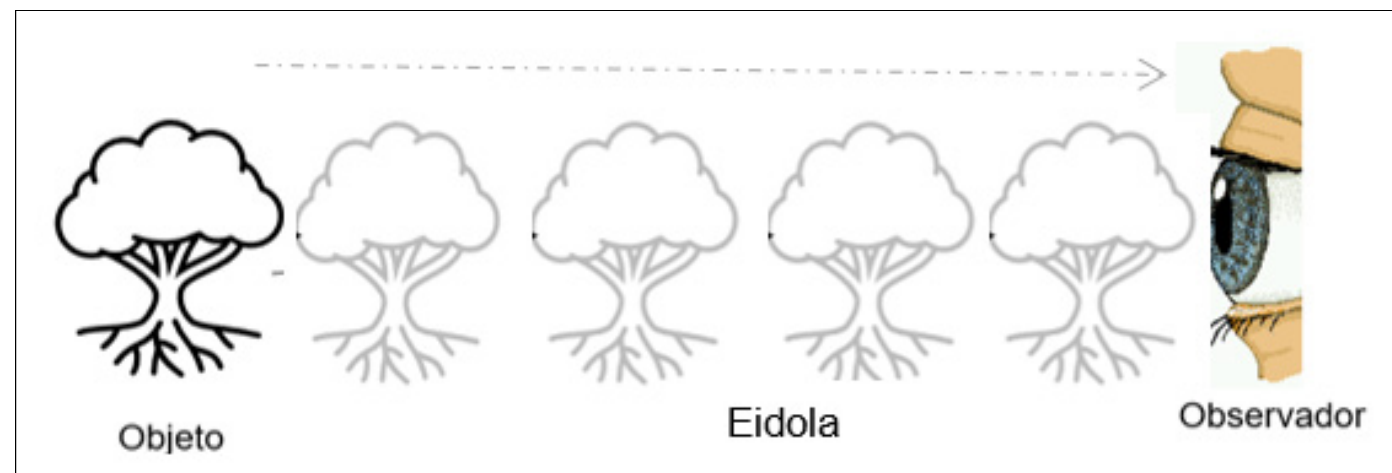

Fonte: autores.

O papel passivo do olho-observador é destacado em oposição ao papel ativo desempenhado pelo objeto. $\mathrm{O}$ olho tem o papel de receptor da imagem através da retina, havendo assim uma independência entre o objeto e o observador

Por outro lado, os pitagóricos que estabeleceram sua escola em Atenas, por volta de 388 a.C, postularam a existência de uma substância chamada quid que sai do olho e vai até o objeto para senti-lo (AUTHIER, 1987). Nesse caso, é o olho que tem o papel de transmissor do ponto crucial e o objeto não tem papel na visão. Segundo Authier, essa foi a concepção predominante por muito tempo, com adaptações como a de Aristóteles, que justifica a passividade de alguns órgãos como o ouvido e o nariz, em relação ao papel ativo do olho e do tato devido as formas côncavas e convexas, respectivamente.

A Figura 3 mostra a representação do modelo da visão dos pitagóricos. 
Figura 3: Representação modelo da visão pitagórico

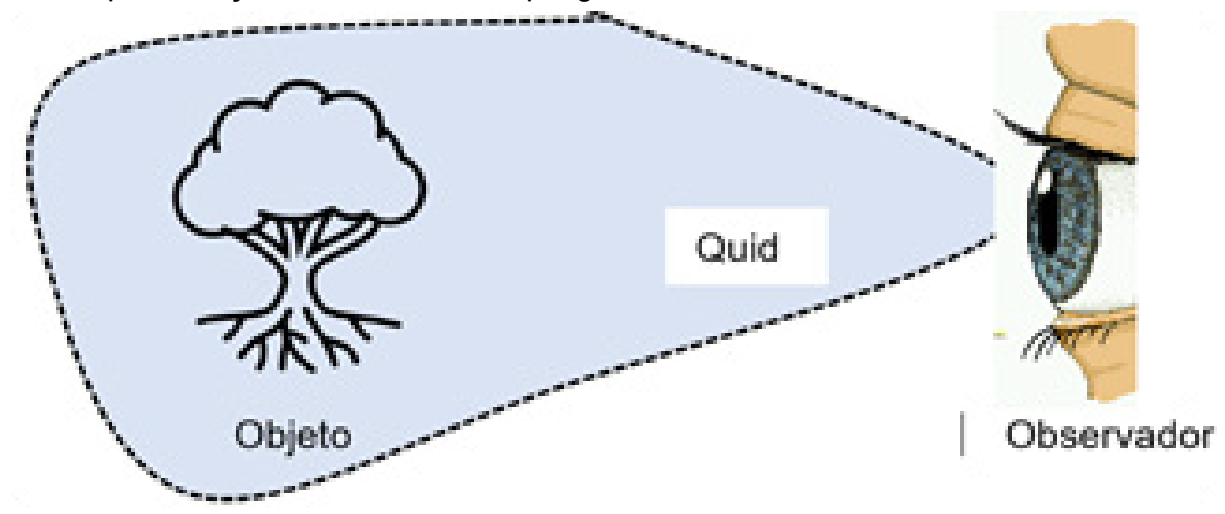

Fonte: autores.

Empédocles (495 aC - $430 \mathrm{aC}$ ), por sua vez, dando continuidade à sua teoria, propõe que o encontro entre semelhantes ocorre no ar e se combinam transmitindo movimentos por todo o corpo à alma. O objeto e o olho têm um papel ativo, pois ambos são transmissores. Além disso, o ar entra para desempenhar um papel principal, pois é o meio no qual são encontrados "semelhantes".

Quando a luz do dia envolve o raio visual, este transborda - o semelhante procura o semelhante - e com ele funde-se; um corpo único - combinado com o nosso - é constituído ao longo da linha que sai dos nossos olhos, onde quer que o fogo que surge do nosso interior encontre o que vem dos objetos externos [...]. Ele transmite os movimentos por todo o corpo para a alma, e dá-lhe aquela sensação em virtude da qual afirmamos ver (PLATÃO, TIMEU, citado por AUTHIER, 1989, p. 289).

A Figura 4 representa o modelo da visão do Empédocles:

Figura 4: Representação modelo da visão de Empédocles.

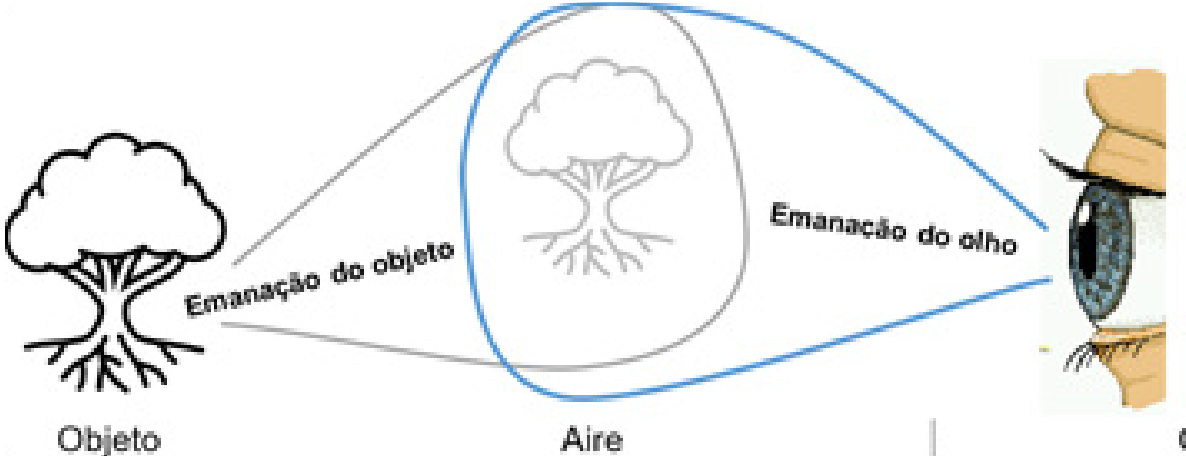

Observador

Fonte: autores. 
Platão, considera que luz e visão são independentes. Seguindo a tradição pitagórico-platônica, adiciona novos elementos. Assim, para Platão, a discussão não se concentra na relação sujeito-objeto, mas na dependência que as teorias anteriores declararam entre luz e visão. Para ele a existência da luz ocorre independente da visão e, portanto, a relação com o conhecimento e a verdade pode ser justificada. No entanto, um elemento que ele adiciona ao modelo de visão dos pitagóricos é a presença da luz solar. Embora a fusão seja mantida como um processo necessário para produzir a imagem, é necessário que a fusão entre a emanação do olho e a luz solar ocorra. A este respeito, Rodrigues Neto (2013, p. 875) menciona:

A doutrina visual de Platão é mais elaborada do que essa versão simplificada e requer, ainda, que essa emissão a partir do olho - essa "mão visual" - sofra aquilo que a tradição denominou de "coalescência" (synaugeia) com a luz do Sol (cf. Beare, 1906, p. 45, nota 1). Com isso, Platão parece multiplicar as entidades, uma vez que sua doutrina requer, ademais da emissão a partir do olho, uma emissão de luz a partir do Sol.

Aristóteles, ao debater as teorias anteriores, argumenta que nada pode emanar nem do olho nem do objeto, pois no primeiro caso seria possível ver dia e noite sem a presença de uma fonte de luz, ao passo que, na segunda, sempre seria possível encontrar um objeto, por menor e misturado que fosse. Assim, para ele o que existe é uma alteração do espaço intermediário que pressiona o olho e desaparece com a escuridão. Além disso, para Aristóteles, a ênfase está nas propriedades do espaço intermediário ao qual a propriedade de afetar o olho é atribuída. Nada emana do olho ou do objeto, mas é o ambiente que sofre uma alteração que o leva a afetar o olho, estabelecendo assim uma espécie de continuidade entre o olho-objeto-espaço intermediário. A luz aparentemente tem a propriedade de ser transparente, então o espaço intermediário também é transparente. Esta propriedade de ser transparente à luz caracteriza sua natureza. Da mesma forma, para ele, cor é o que o olho recebe, ou seja, é o "próprio sensível" da visão que é recebido em sua própria forma: o olho.

Até agora pode-se perceber que os diferentes modelos vindos dos gregos mostram uma riqueza na compreensão do fenômeno óptico e uma complexidade no tratamento dos fenômenos associados à luz e a visão intimamente ligada aos sentidos, ou seja, a sensação visual. Como Authier (1989) menciona "Uma pré-condição da visão, a luz é, no pensamento grego, o intermediário quintessencial entre o espírito e o mundo". Isso explica a complexidade que está contida em cada um dos modelos que pretendem dar conta da luz e da visão, mas que unem elementos que hoje chamaríamos de fisio- 
logia, filosofia, física e epistemologia. Desta maneira, as doutrinas filosóficas gregas que visavam descrever as formas como ocorre a sensação visual, desenvolvidas por teorias anteriores à Euclides, podem ser caracterizadas de acordo com (TOSSATO, 2005 citado por RODRIGUES NETO, 2013, p. 879) da seguinte maneira:

Todas essas doutrinas filosóficas centravam sua atenção nos processos físicos subjacentes à experiência visual, todas elas faziam diversas considerações a respeito da natureza do mundo e também a respeito da natureza do próprio órgão sensorial da visão - o que influenciou a tradição médica e suas considerações acerca da estrutura anatômica e das afecções do olho.

Aprofundando-se nas características dessas doutrinas e pensando em modelos científicos, é importante resgatar a obra do historiador norte-americano David Lindberg (1976), que fez uma classificação dessas doutrinas filosóficas, identificando duas categorias de explicação: extramissão e intromissão (LINDBERG, 1976). Na primeira considerou-se que a percepção visual é o produto da emissão do objeto que entra em contato com o olho, é o caso dos atomistas. Na segunda categoria, a explicação é baseada na emanação do olho e no contato com o objeto. No entanto, essas duas categorias deixam de fora os modelos híbridos (RODRIGUES NETO, 2013), pois, ¿em qual categoria poder ia-se colocar as doutrinas de Demócrito ou Platão, por exemplo? O que chama a atenção para fins didáticos, no sentido de caracterizar as diferentes doutrinas, é questionar o caráter passivo/ativo do olho e sua relação com a luz. Uma condição necessária para "ver" é a fonte de luz, mas isso terá que esperar por posteriores desenvolvimentos.

\section{A óptica geométrica dos gregos}

Avançando nos modelos gregos, um nome pouco reconhecido na história da ciência é o de Arquitas de Tarento ( $430 \mathrm{aC}$ - cerca de $360 \mathrm{aC}$ ), contemporâneo de Platão e pertencente à escola pitagórica. Ele é creditado com uma influência notável no trabalho de Euclides em óptica.

Retomando o raio e a propagação da luz a partir do modelo proposto por Architas de Tarento, Euclides inaugura a tradição da óptica geométrica e consegue aproximar a física da matemática, despojando o problema da visão de sua relação com os elementos (terra, água, ar, fogo, éter) e das sensações que ocorrem no sujeito (AUTHIER, 1989). 
Os postulados de Euclides simplificam o modelo de visão em um único olho, um raio em uma direção e o cone visual que sai do olho e vai até o objeto, ligando elementos práticos que foram trabalhados na astronomia e na teoria das proporções geométricas. A seguir, resgatamos as definições que fundamentaram a Óptica de Euclides da tradução feita por Rodrigues Neto (2013, p. 894):

Definições: 1) Seja suposto que linhas retas traçadas a partir do olho atravessam uma distância de grande magnitude. 2) E que a figura contida pelos raios visuais é um cone, cujo vértice encontra-se no olho e sua base nos limites daquilo que é visto. 3) E que aquilo sobre o qual os raios visuais incidem é visto e aquilo sobre o qual os raios visuais não incidem não é visto. 4) E que, a partir de um ângulo maior, aquilo que é visto aparece maior, a partir de um menor, menor, e a partir de ângulos de visão iguais, igual. 5) E que, a partir de raios visuais mais altos, aquilo que é visto aparece mais alto, a partir de mais baixos, mais baixo. 6) E, similarmente, que, a partir de raios visuais mais à direita, aquilo que é visto aparece mais à direita, a partir de raios visuais mais à esquerda, é visto mais à esquerda. 7). Enfim que, a partir de um maior número de ângulos, aquilo que é visto aparece mais distintamente.

Destas definições os raios visuais e o cone visual se destacam e explicam o que Aristóteles chamou de "sensível comum", ou seja, a forma, a distância, o tamanho e o movimento. Portanto, pode-se dizer que na óptica de Euclides estuda-se a percepção da forma e do tamanho, mas não se explica a cor.

A Figura 5 mostra uma representação do modelo visual de Euclides.

Figura 5: Representação do modelo de visão de Euclides
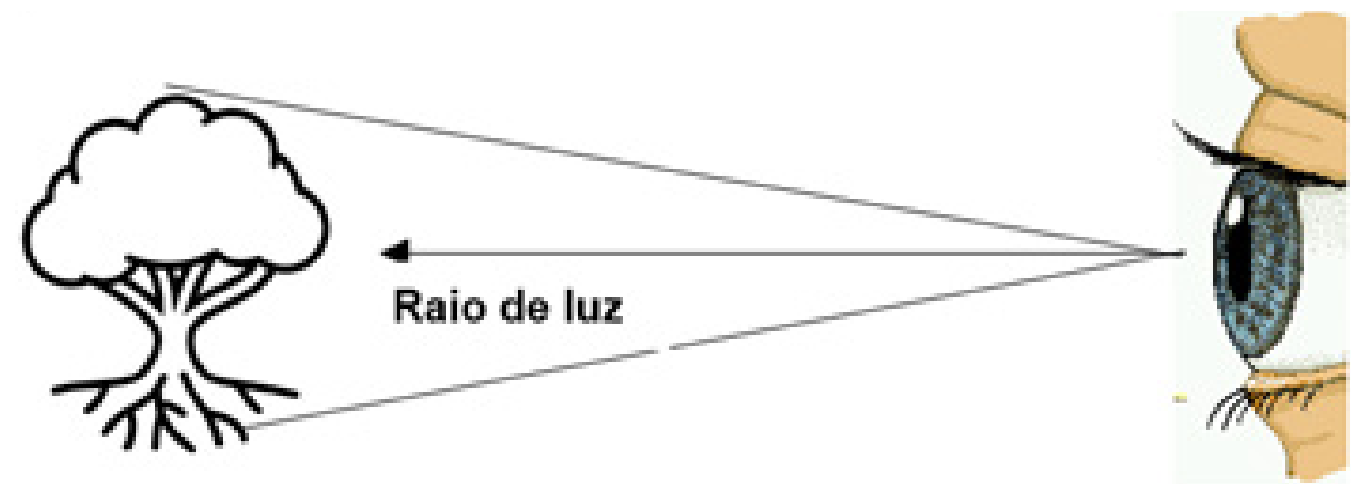

Objeto

Olho

Fonte: autores.

A simplicidade do trabalho de Euclides configura o sucesso para a empresa astronômica, visto que foi a partir de sua teorização que pode-se explicar a relação 
luz e imagem levando em consideração elementos matemáticos semelhantes ao cone, à linha reta e aos ângulos. Authier (1989, p. 291) menciona: "A luz perde toda a substância, os raios são governados por uma geometria elementar, um único olho participa da visão e o mundo é reduzido a uma representação visível da direita ou esquerda, de cima ou de baixo".

O processo que Euclides descreve, embora despojado dos problemas da sensação visual, está inscrito na tradição platônica, onde o olho é ativo porque dele emanam raios visuais que atingem o objeto. Com os desenvolvimentos de Alhacén e Kepler, tal descrição se tornará o maior obstáculo desde que a falsidade da doutrina da extramissão é demonstrada. Segundo Rodrigues Neto (2013, p. 882), o que permite que a visão seja geometrizada é: "que a visão é definida por um "cone de raios visuais", isto é, uma "figura geométrica" constituída por uma coleção de "linhas retas" divergentes, uma figura que tem como sua base aquilo que é visto e como seu vértice o olho, ou a origem da emissão ocular".

Por fim, as contribuições do trabalho de Euclides para a óptica geométrica vão além da explicação da visão e configuram um caráter prático que é utilizado por pintores, arquitetos, entre outros, pois ao trabalhar com tamanhos, formas e distâncias, foi possível descrever uma óptica que considerou a posição do olho em diferentes pontos, ou seja, passou-se a ponderar a questão da relatividade visual.

Em síntese, frente aos modelos gregos da visão, reconhece-se três preocupações inerentes: 1) a natureza e a propagação da luz; 2) a formação de imagens; e 3) a cor. Da mesma forma, Rodrigues Neto (2013), retomando a obra de Gérard Simon (2003), afirma:

Como bem observa Gérard Simon, na óptica antiga, a luz jamais aparece como "protagonista" do processo visual (cf. Simon, 1988, p. 11, 22-25). Com efeito, a óptica antiga não se constituiu como uma "física da luz", mas em uma "geometria da visão", e a noção de "raio de luz", tal como delineada na óptica moderna, jamais manifestou-se na ciência antiga. (cf. Simon, 2003, p. 20) citado por (RODRIGUES NETO, 2013, p. 882)

Sendo assim, pode-se inferir que ao longo da história foi definida a entidade física "luz", delimitando o campo de fenômenos e problemas relacionados ela, a visão e "a luz foi descarregada dos problemas consideráveis que sua natureza apresenta, dividindo a óptica física em três: perspectiva, catóptrica e dióptrica" (AUTHIER, 1988). Portanto, embora a óptica, do ponto de vista grego, seja mais uma filosofia da visão, ela gerou contribuições importantes ao questionar o papel 
do olho, o objeto, a fonte de luz por excelência que é o Sol e o papel do observador na sensação visual.

\section{Contribuições de Alhacén para a óptica}

Um dos físicos árabes que mais contribuiu para a construção de modelos sobre a luz e, em particular, para a óptica geométrica foi Alhacén (965-1040). Seus trabalhos no estudo do olho, visão e astronomia são reconhecidos porque ele retoma os postulados aristotélicos afirmando que "no mecanismo visual tudo é refração" e renova o problema da percepção, invertendo o modelo de propagação proposto por Euclides, isto é, passa de um modelo de extramissão para um modelo de intromissão de visão. González-cano (2015), afirma que a Óptica Alhaceniana funda a óptica que conhecemos hoje, pois apresenta a luz como agente físico protagonista e consegue unificar campos tão diversos como astronomia, anatomia do olho, fenômenos atmosféricos, doenças oftalmológicas, entre outros. Portanto, é possível considerar suas contribuições como uma verdadeira revolução na óptica. Tal reconhecimento pode ser vislumbrado por meio da seguinte citação que Sabra (1989) citado por González-cano (2015) retoma de Alhacén (1028-1038):

Fica assim evidente que o olho não percebe nenhum objeto visível que não contenha alguma luz, seja ela própria ou proveniente de outro objeto (...). Devemos agora investigar as propriedades da luz e seu modo de radiação, e então estudar o efeito da luz na visão. A isso devemos então adicionar o estudo do olho, a fim de, por meio de um raciocínio cuidadoso, prosseguir em nosso caminho para a conclusão (SABRA, 1989 citado por GONZÁLES-CANO, 2015, p. 6).

Alhacén estudou as obras de Ptolomeu, Euclides e Galeno e propôs uma nova forma de investigar os fenômenos ópticos em seu livro Kitab al-Manazir, que posteriormente foi traduzido e divulgado sob o nome de "perspectiva" (GONZÁLEZ-CANO, 2015), no qual detalhou uma série de observações experimentais que tratam do problema da visão e da interação do olho com a luz. A análise física da luz e o uso de elementos matemáticos para modelar as interações dos raios com o olho são elementos que se destacam em seu trabalho. Nesse sentido, a abordagem pontual que propôs é fundamental para passar da extramissão à intromissão. O que se segue são observações extraídas do trabalho de Sabra (1989) citado por González-cano (2015, p. 10) que mostram o quadro dos fatos estabilizados na óptica até o trabalho de Alhacén: 
a) Primeiro, deve haver uma certa distância entre o olho e o objeto. Não há visão se houver contato direto com o olho, embora o objeto seja visível e, como tal, típico da percepção visual, só há visão se o objeto for colocado na frente do olho, de forma que uma linha reta possa ser tirada de cada ponto o objeto para o olho, e desde que não haja obstáculos opacos que interrompam essas linhas imaginárias

b) A visão não percebe nenhum objeto visível, a menos que haja naquele objeto alguma luz, seja ela própria, ou proveniente de algum outro objeto que irradia sobre ele. Se o objeto for escuro e não tiver luz, não pode ser visto a olho nu.

c) Se o olho está localizado em um local escuro, ele pode perceber os objetos à sua frente se estiverem iluminados, desde que a atmosfera intermediária seja contínua e não haja obstáculos opacos, mas se o objeto estiver em um local escuro onde não há luz e o olho está localizado em um lugar iluminado, o objeto não pode ser percebido. E este estado de coisas é sempre mantido sem qualquer variação.

d) Que o objeto visível tem um determinado tamanho, já que não se percebem objetos extremamente pequenos, como (diz ele, por exemplo) a pupila do olho de um mosquito, de cuja existência não teríamos que duvidar.

e) Corpos dotados de uma certa opacidade, além disso, apresentarão uma certa cor (como uma qualidade visível, uma propriedade diretamente acessível a olho nu), o que pode não ocorrer em meios totalmente transparentes, que, portanto, permanecem invisíveis.

A análise rigorosa de cada um desses elementos foge ao propósito deste artigo. Contudo, torna-se pertinente destacar três dados que apresentam elementos resgatados da experiência: a) a imagem formada é ponto a ponto, portanto, não é um raio visual único, mas raios múltiplos, b) o papel da fonte de luz para que a visão ocorra, c) os limites físicos da visão e as propriedades dos corpos e do meio. Assim, a relação olho-fonte-objeto está sendo configurada a partir de uma perspectiva de intromissão.

Na mesma linha, ao estudar o olho e se perguntar sobre a percepção da imagem, ele reconhece na refração (sem usar o termo) uma forma de explicar a deflexão dos raios de luz. $\mathrm{O}$ trabalho de Alhacén é rigoroso no que diz respeito a mostrar evidências empíricas do raio de luz como uma entidade física, já que até então o raio visual era compreendido como uma representação geométrica funcional. A 
esse respeito, Authier (1989) menciona uma observação que Alhacén faz sobre o movimento e a velocidade da luz em diferentes meios: "As luzes que se propagam por corpos transparentes o fazem com um movimento muito rápido, inestimável por sua velocidade. Porém, seu movimento através de corpos magros, ou seja, diáfanos, é mais rápido do que seu movimento em corpos grossos"

Depois de estudar as características da luz ao passar por diferentes meios e mostrar a existência física do raio e seu caráter retilíneo através do estudo da velocidade em diferentes meios, ele se concentra em como o olho reage à luz por meio da dor (GONZÁLEZ-CANO, 2015). Retomando os estudos e modelos de visão de Galeno, ele estabeleceu um modelo do olho no qual todos os elementos têm uma forma esférica e seus centros estão em um eixo que passa pelo centro da pupila. Assim, para Alhacén os raios de luz entram no olho e é o cristalino que faz o trabalho de formação da imagem. Isso será corrigido posteriormente no trabalho de Kepler, pois ele verificará que é na retina onde a imagem é formada. Porém, ao enfatizar a refração que ocorre no olho, ele estabelece o problema fundamental que será abordado posteriormente pela óptica geométrica e a fisiológica (AUTHIER, 1988, p. 294).

Para explicar a formação da imagem dentro do olho, ele usa a refração e a seleção de um único raio de luz que entra no olho e é capaz de gerar o estímulo. González-cano (2015, p. 11) menciona:

de cada ponto do objeto a cada ponto da lente haverá apenas uma trajetória que pode alcançar tendo cruzado todas essas superfícies perpendicularmente, e uma réplica do objeto pode ser recomposta na lente, salvando assim o esquema de perspectiva e recuperando o cone visual, agora formado pelos raios de luz que entram no olho

Como pode-se observar, essa óptica está muito longe de suas antecessoras, pois foi recoberta por uma estrutura matemática e entidades físicas que modelam o fenômeno da visão. Isso, longe de ser uma simplificação do problema da visão, representa uma mudança na forma como o problema em si é colocado, o que mostra que a ciência não é cumulativa nem linear. Nos trabalhos desenvolvidos até então o problema foi se transformando e tornando-se mais complexo, pois apesar das relações com outros elementos como as sensações, o espírito, entre outros, tenha sido deixadas de lado, os vínculos com a matemática, a astronomia, a fisiologia e os meios pelos quais a luz se move, têm efeitos diferentes. Esta será a estrutura óptica mais robusta e na qual o trabalho de Kepler em particular será baseado. 


\section{A câmera escura: pensando a tecnologia e sua relação com ciência}

Conforme discutido até o momento, aos poucos foi se transformando a forma de abordar o problema da visão e os fenômenos que se enumeram nas relações luz-visão. Nesse sentido, o desenvolvimento de técnicas de vidro e o uso de lentes convergentes no século XIII para corrigir problemas de visão, os trabalhos de Della Porta (1535-1615) com a câmera escura e os de Kepler (1571-1630) em astronomia com o desenvolvimento de telescópios e na óptica, contribuíram para essas transformações e para a consolidação do campo da óptica geométrica. Este caminho trilhado por diferentes grupos, como filósofos, artesãos, pintores, astrônomos, matemáticos, entre outros, possibilitou o estabelecimento de um modelo que tem na sua base uma entidade física com um "pé" na representação matemática e outro no mundo físico. Assim, o modelo de raio visual de Euclides foi transformando-se em raio de luz com o trabalho de Alhacén, tornando a luz a entidade principal da visão. Essa mudança é talvez uma das mais notáveis na Óptica.

Entretanto, esta mudança precisa ser complementada por uma reflexão sobre o papel da tecnologia a partir de uma dimensão humana, na qual a tecnologia constitui o homem, visto que atravessa a existência humana como fonte de resolução de problemas e transformação da natureza para fins sociais (THOMAS; FRESSOLI; LAFOUF, 2008). Assim, o papel da câmera escura e do vidro para a produção de lentes e telescópios na construção da fenomenologia na óptica e no desenho de instrumentos ópticos foi muito importante. Em princípio, teremos que dizer que o fenômeno da câmera escura recebe o mesmo nome do artefato que evoluiu para se tornar um dispositivo portátil.

Assim, considerando as contribuições de Hugues (2008), pensar no artefato, ou seja, a câmera escura, implica também perguntar sobre o sistema tecnológico por trás, isto é, seus componentes, organizações, outros artefatos associados e os problemas superados, pois os sistemas tecnológicos são socialmente construídos e configuram a sociedade (HUGUES, 2008). Nesse sentido, é possível que Alhacén utilizasse a câmera escura para fins astronômicos e científicos, mas quando chegou à Itália, os pintores renascentistas a utilizaram para criar suas pinturas e estudar perspectiva, cores e sombras. Segundo Tossato (2007), que astrônomos e ópticos tinham um grande interesse pelo funcionamento e uso da câmara escura, o que os conduziu a associarem este instrumento com o olho, o que pode nos dar uma ideia 
dos grupos sociais que estiveram por trás da estabilização da analogia entre o olho e a câmera escura.

Kepler, fez parte de tais grupos sociais e foi um estudioso da mecânica celeste (entendida como os problemas do movimento) sob o pressuposto das leis de causa e efeito, que realiza o giro do olho como um dispositivo mecânico. No enfoque kepleriano o olho é um artefato mecânico que recebe informações, os raios de luz, e atua sobre eles segundo as suas características, isto é, de acordo com as funções de cada um dos seus componentes (partes do olho) e da relação entre eles. Assim, no modelo de olho kepleriano, é analisada a quantidade de raios que entra pela pupila e como esses raios passam ao interior do olho, por refrações de cada raio: a primeira na córnea e a segunda no cristalino, obtendo-se a imagem: a pintura do objeto na retina (TOSSATO, 2007, p. 490).

\section{Estabelecendo a analogia olho-câmera escura}

O princípio da câmera escura foi estudado por Aristóteles (384-322 aC), Mo Tzu (468-376 aC), Al-Kindi (795-873) e Alhacén (965-1040), mas este último foi quem recebeu o crédito por sua invenção como artefato. O próprio Alhacén reconheceu que a produção de imagens invertidas, recolhidas por um ecrã localizado numa sala escura, após a passagem da luz por um pequeno orifício, já era bastante conhecida, razão pela qual a sua utilização para o estudo do mecanismo da visão talvez seja sua maior contribuição (Fraga, 2016). Considera-se também que os estudos que desenvolveu com a câmera escura se devem ao seu interesse pela astronomia, já que se sabe que ela servia de instrumento para observar eclipses e que também foi utilizada para comprovar que raios de luz e cores não se misturam no meio que passam. Observemos um trecho da obra de Alhacén (1040) a esse respeito, retomado por Cardona (2020, p. 379):

A evidência de que a luz e a cor não se misturam no ar ou em [outros] corpos transparentes é [encontrada] no fato de que, quando várias velas estão localizadas em vários lugares diferentes na mesma área, e quando todas elas estão voltadas para um janela que dá acesso a uma cavidade escura, e quando há uma parede branca ou corpo [outro] opaco [branco] voltado para a janela na cavidade escura, as luzes [individuais] dessas velas aparecem individualmente no corpo ou na parede de acordo com o número de tais velas; e cada uma dessas [manchas de luz] aparece diretamente em frente a uma vela [particular] ao longo da linha reta que passa pela janela. Além disso, se uma vela for coberta, apenas a luz oposta à vela será apagada, mas se o obstáculo que ela cobre for levantado, a luz retorna. 
Ao chegar à oeste a câmera escura passa por modificações em seu uso e mecanismos, por exemplo, acredita-se que Da Vinci (1452-1519) foi o primeiro a adicionar uma lente ao orifício da câmera escura para melhorar a nitidez da imagem e postular a analogia entre a câmera escura e o olho. Com Della Porta e sua obra Magia Naturalis (1558), amplamente difundida, popularizou-se o uso da câmera escura na ciência, na arte e como brinquedo.

Aristóteles havia mencionado alguns problemas com relação à imagem que é coletada quando a luz passa por um orifício com formas retangulares ou poligonais. Isso também pode ser notado em um eclipse solar sendo um dos mais belos fenômenos que podem ser testemunhados em poucos minutos. Abaixo está uma fotografia tirada em 11 de agosto de 1999 no campus da Northwestern University em Evanston, Illinois, intitulada "Eclipse In The Shade":

\section{Figura 6: Eclipse}

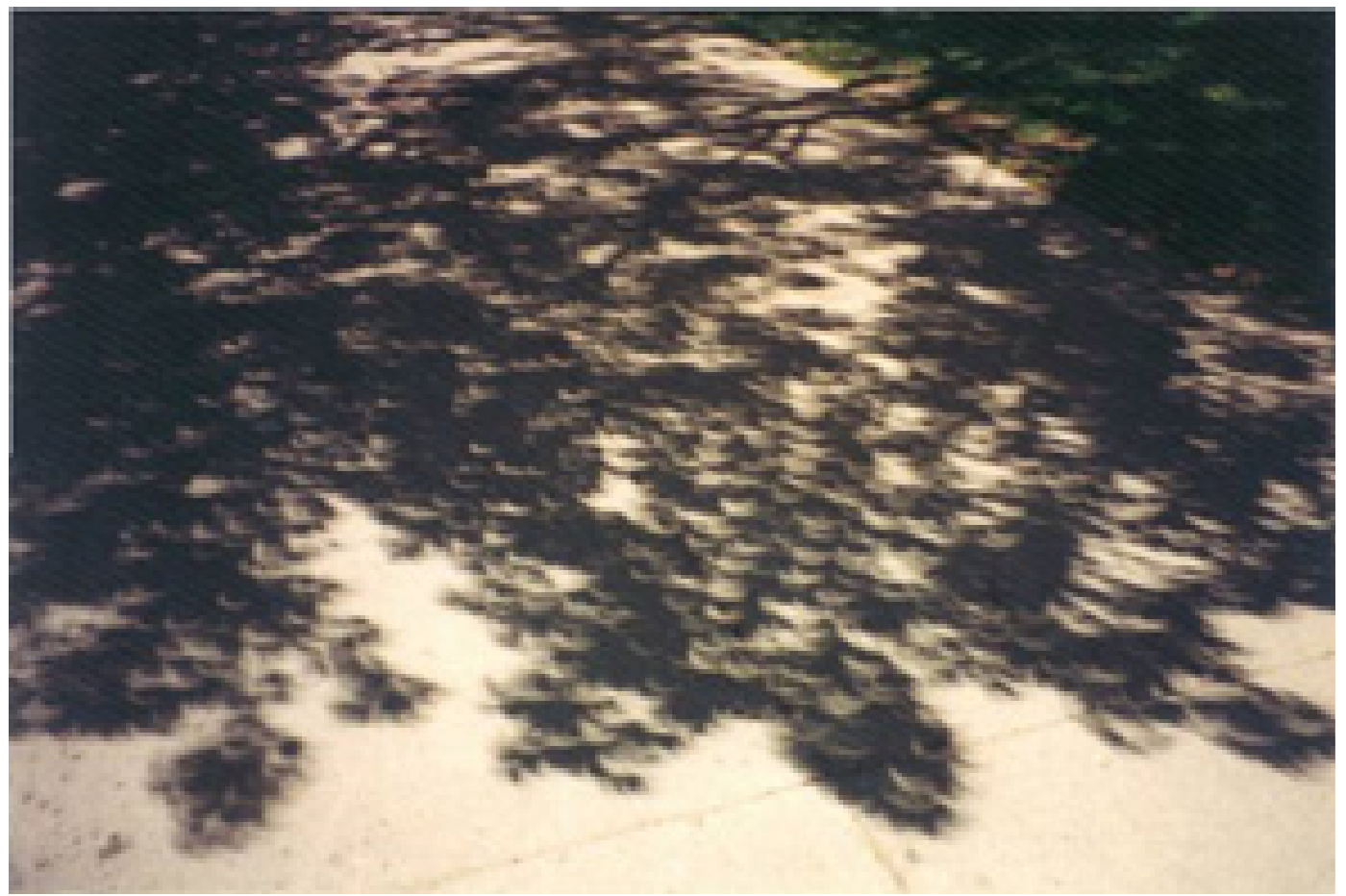

Fonte: In The Shade Credit and Copyright: E. Israel.

https://apod.nasa.gov/apod/ap990813.html. 
Justamente, o próprio Da Vinci, ao explorar o funcionamento da câmera escura, menciona que:

Eu digo que se a frente de um edifício - ou qualquer praça aberta ou campo - que é iluminada pelo sol tem uma morada oposta a ela, e se, na frente que não está voltada para o sol, você faz um pequeno buraco redondo, todos os objetos iluminados projetarão suas imagens por aquele orifício e serão visíveis no interior da habitação na parede oposta que pode ser branca; e lá, de fato, eles ficarão de cabeça para baixo, e se você fizer aberturas semelhantes em vários lugares na mesma parede, terá o mesmo resultado em cada um. Consequentemente, as imagens dos objetos iluminados estão todas em toda parte nesta parede e todas em cada parte mais ínfima dela. A razão, como bem sabemos, é que este orifício deve admitir alguma luz à dita habitação, e a luz por ele admitida provém de um ou mais corpos luminosos. Se esses corpos são de várias cores e formas, os raios que formam as imagens são de várias cores e formas, e o mesmo ocorre com as representações na parede. (Tomado de The Notebooks of Leonardo da Vinci e editado pelo Jean Paul Richter, 1880. ${ }^{1}$ ).

Na verdade, Steadman, (2011) afirma que Caravaggio, Canaletto e Vermeer pintaram com a ajuda da câmera escura. Portanto, não é raro que em diferentes textos de Leonardo Da Vinci, observaram-se análises da perspectiva e do funcionamento da câmera escura e do olho e portanto que historiadores como Vasco Ronchi (CARDONA, 2020) lhe atribuem ser o primeiro a estabelecer a relação entre o funcionamento do olho e esse fenômeno, que por sua vez é um dispositivo. No manuscrito D, Leonardo Da Vinci descreve algumas ideias sobre o funcionamento do olho e a formação da imagem. Muitas dessas são similares às encontradas na obra de Alhacén, que os historiadores acreditam ter sido difundida através das obras de Bacon e Vitelo.

Para estabelecer a analogia do funcionamento do olho com a câmera escura, é necessário determinar a correspondência entre os elementos, neste caso, a pupila atua como o orifício por onde passa a luz na câmera escura. Porém, mesmo para Da Vinci, a imagem não é coletada na retina, por isso ele elabora diferentes explicações para a recepção da imagem pelo nervo óptico através do cristalino. Um problema relevante a esta temática está relacionada com a inversão da imagem obtida, sob o qual surgem questionamentos, dentre eles: Como a imagem é invertida, depois de entrar no olho, para que percebamos o objeto na posição correta? Tal problemática foi objeto de suas reflexões acerca da dupla inversão no olho. Da Vinci é reconhecido por suas imagens e modelos anatômicos do corpo humano, com os quais, neste tratado, alguns de seus comentários são acompanhados de desenhos. A seguir apresentamos 
um destes comentários, resgatado de Cardona (2020, p. 165) em que Da Vinci tenta explicar o funcionamento da pupila e da esfera cristalina:

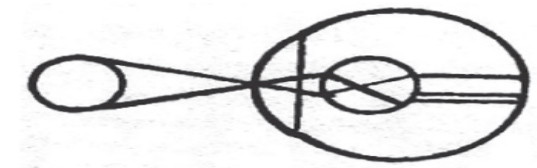

FIGURA 15. (TP $\$ 78)$

A necessidade previu que todas as imagens (spetie) de objetos na frente do olho se cruzam em dois lugares. Uma dessas interseções ocorre na pupila, a outra na esfera cristalina; caso contrário, o olho não seria capaz de ver tantas coisas quanto vê [...] nenhuma imagem (spetie), mesmo do menor objeto, entra no olho sem ser invertida; mas ao penetrar na esfera cristalina ela reverte novamente, e assim a imagem (spetie) aparece à direita dentro do olho, como o objeto estava à direita fora do olho ». (tp §78).

Desta forma, a partir dessas discussões, observou-se algumas problemáticas que devem ser levadas em consideração para que a analogia do olho e da câmera escura seja aceita, estabelecendo-se em um modelo que tem uma parte no mundo real e outra na teoria.

\section{Kepler e seu estudo sobre a imagem no olho}

O trabalho de Kepler tem um interesse especial, pois consegue ligar a astronomia, a visão e a refração da luz e gerar uma teoria sobre tais conteúdos. A esse respeito, Authier (1989) menciona: "Sua obra é um grande caldeirão onde todas as teorias herdadas são mexidas: "Fiz este trabalho imenso e austero atingindo o núcleo de questões abandonadas há séculos, cada uma das quais poderia compor um livro particular" Kepler, citado por Authier (1989). Em seus estudos, Kepler faz questionamentos sobre o problema da visão, rejeitando alguns postulados de Bacon e Galeno e discutindo o que, até então, havia se estabelecido como um modelo geométrico válido de visão. Deve-se mencionar tal trabalho em óptica foi relevante para o Kepler na solução de problemas astronômicos, como a diminuição do diâmetro da lua em conjunção e seu aparente diâmetro maior em oposição ao sol, e isso leva a uma mudança de foco na óptica que acabariam demarcando seu campo de ação. Crombie, (1991) citado por Tossato, (2007, p. 89) afirma: "ninguém tinha tratado com a suposição essencial que a fisiologia ocular funciona como uma explicação imediata da percepção visual; entendiam que ver um objeto é ver apenas o que está presente na imagem formada no olho".

Antes de iniciar a análise das principais contribuições da teoria da visão Kepler e da delimitação da óptica, é importante apontar as seguintes dificuldades que 
retomamos de Cardona (2020) para estabelecer a analogia entre o olho e a câmera escura que também foi objeto de estudo em sua obra e para a qual lhe é atribuído o desenvolvimento da ideia do olho como instrumento de visão, como sistema mecânico: 1) Uma solução matemática para prever / explicar a formação de imagens quando a luz passa por pequenos orifícios 2) uma lei quantitativa precisa para prever o comportamento da luz ao passar por meios transparentes 3) A entidade que recebe a imagem variável de objetos externos ao olho e a forma como mostra essa variação.

Agorá, o "Ad Vitellionem paralipomena, quibus astronomiae pars optica traditur" ou simplesmente Paralipomena foi escrito e publicado pelo Kepler em 1604 e consiste em cinco livros que tratam da luz, a câmera escura, a catóptrica, a dióptrica e o modo de visão (TOSSATO, 2007). Um dos problemas que ela levanta e que reflete a intenção de levar o problema da visão para a mecânica é o seguinte: "Numa câmara fechada [escura], e contra uma parede interposta, represente tudo o que está fora e oposto à câmera" (Paralipomena 67; gm 55). Em seu estudo, são constatados que a imagem projetada na parede da câmera depende do tamanho e formato do orifício, bem como da forma e da distância do objeto da fonte (TOSSATO, 2007). Ao analisar a anatomia do olho, em seu livro V, ele reconhece que a pupila é a encarregada de inserir os raios visuais no olho, mas a maior mudança no que diz respeito à tradição Galena e aos trabalhos de Alhacén é determinar que a retina é aquela que se conecta com o nervo óptico, portanto não é o cristalino o responsável por coletar a imagem formada no olho. A esse respeito Tossato (2007) traz um recorte das reflexões de Kepler:

\begin{abstract}
Se se coloca um eixo passando pelo centro da abertura da coróide no nervo óptico, os centros dos círculos do cristalino estarão sobre esse eixo; assim, têm-se razões para dizer que o cristalino está no centro do olho, se se entender que o olho está cortado por um plano perpendicular ao eixo, e que o centro do olho é o centro do círculo. Mas em relação ao conjunto da forma globular do olho, o cristalino situa-se mais à frente de um tal eixo. O cristalino está mais afastado do término do nervo óptico, e está mais para a abertura da coróide, que é muito menor que a abertura da córnea (Kepler, 1938 [1604], p. 151; 1980 [1604], p. 316).
\end{abstract}

Tal constatação não só determinou uma mudança na compreensão da anatomia e da funcionalidade do olho e de suas partes, mas também marcou o limite da óptica, uma vez que a retina se estabelece como o limite entre a óptica e outras ciências associadas à percepção. Nas palavras do próprio Kepler citado por Tossato, (2007): 
Digo que há visão quando uma representação de todo o hemisfério do mundo, situado diante do olho [...] fixa-se sobre a parede branco-rosácea da superfície côncava da retina. Deixo para os filósofos naturais discutirem o modo pelo qual essa representação ou pintura une-se aos espíritos visuais que residem na retina e no nervo, e se ela é levada por esses espíritos para o interior das cavidades do cérebro.

Continuando com as contribuições para a teoria da visão de Kepler, ele usa a ideia de cone visual proposta a partir de Euclides, mas desta vez estabelecendo um cone duplo e invertendo o vértice, do cone, ou seja, agora o vértice está localizado no objeto e a base no olho e isso ocorre com cada um dos pontos do objeto. Assim, o segundo cone divide a base com o primeiro cone e localiza seu vértice em um ponto da imagem gerada na tela. Cardona, (2020), menciona que Kepler consegue estabelecer o que chama de teorema fundamental da óptica e com isso completa a analogia entre o olho e a câmera escura, ou seja:

Eu digo que esta pintura [aquela coletada na retina] consiste em tantos pares de cones [conorum] quantos pontos no objeto visto. Esses pares têm a mesma base, a amplitude do humor cristalino, ou uma pequena parte dele, então um dos cones é arranjado com seu vértice no ponto visto e sua base na lente (embora isso seja ligeiramente afetado pela refração que ocorre na córnea), enquanto o outro tem a base na lente, semelhante ao primeiro cone, e o vértice em algum ponto da pintura atinge a superfície da retina, após sofrer refração originada da lente (Paralipomena 182; gm 153).

Suas análises do comportamento dos raios dentro do olho mostram o papel da refração e da lente nos processos de refração dupla. É notável nessas análises o uso da geometria para explicar o comportamento do feixe de luz dentro do olho, pois para o Kepler, a luz não tem massa e sua velocidade é instantânea, portanto, não "toca" as partes do olho.

O trabalho de Kepler é retomado anos depois por um holandês chamado Willebrord Snell (1591-1626), que propõe a lei da refração da luz e que pressupõe uma virada radical do problema da refração, pois seu foco passa de: ¿que fenômenos são produzidos pela refração? A ¿O que produz a refração?

Para finalizar esta mirada mecanicista da luz na que trabalha Kepler, retomamos o trabalho de Dióptrica de Descartes onde postula o que entende por luz por meio de três metáforas diferentes a) o bastão, b) o fluido e c) minúsculas esferas em movimento constante (Authier, 1988). Este último avança em direção a uma explicação mecanicista da luz que era o desejado por Kepler. A esse respeito, vejamos: 
Por fim, enquanto a ação da luz obedece às mesmas leis do movimento desta bola, deve-se dizer que quando seus raios passam obliquamente de um corpo transparente para outro, ela os recebe com mais ou menos facilidade do que o primeiro e há uma inclinação inferior na parte da superfície onde se encontra o corpo que os recebe mais facilmente do que na parte onde está o outro; e na mesma proporção que aquele que os recebe mais facilmente $o$ faz o outro. Basta atentar para o fato de que essa inclinação deve ser medida pelo número de retas como CB ou A H e EB ou IG [...]. Pois a razão, ou proporção, que existe entre as linhas A H e IG ou, semelhante, permanece a mesma em todas as refrações causadas pelos mesmos corpos (AUTHIER, 1988, p. 309)

Tal compreensão também aparece nas obras de Newton e Huygens, que abordam o problema da refração, cores e velocidade da luz, desde uma postura mecanicista e geométrica, e pode ser explorada nos trabalhos de Alvarado (2017) e Cerquera e Garcia (2016).

Até agora foi visto que os fenômenos que foram coletados para estabelecer um conjunto de fatos físicos, vêm da astronomia, fenômenos cotidianos, anatomia, arte, e outros que geraram a construção de dispositivos ópticos como a câmera escura e o telescópio, sempre com a procura de explicar e delimitar um modelo que explique como vemos e que derivou no comportamento da luz ao passar de um meio para outro. No entanto, outros problemas e fenômenos permanecem de fora.

\section{Conclusões}

Voltando ao conceito epistemológico de analogia (ADURIZ-BRAVO, 2005) que é entendida como recurso do pensamento e da linguagem para a criação de significados, é possível analisar os elementos necessários para consolidar a analogia do olho como câmera escura. Nesse sentido, o modelo analógico olho-câmera escura exigia a construção da correspondência entre os elementos dos dois campos (fonte e alvo), em termos de estrutura e funcionalidade. A seguir, usamos a Figura 7 para mostrar a correspondência entre os elementos: 
Figura 7: Representação da analogia entre o olho e a câmera escura
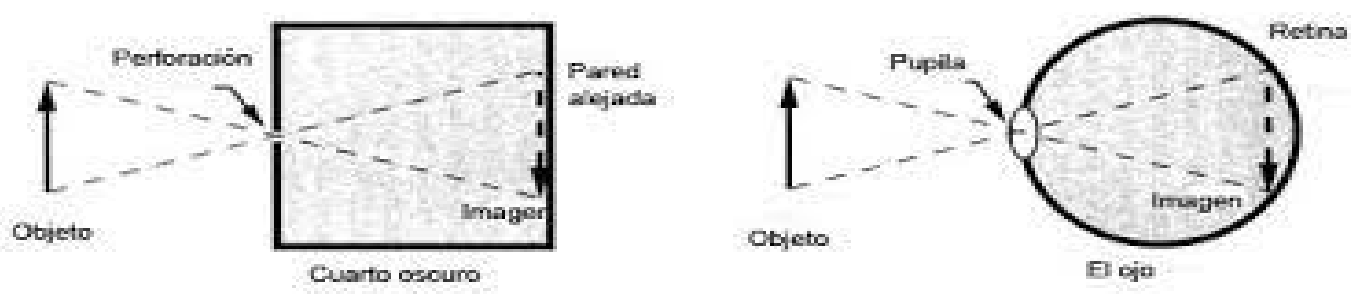

Fonte: https://www.emaze.com/@AOLORWOCO.

A correspondência entre a estrutura da câmera escura e o olho começa com a pequena perfuração e a pupila, logo é necessário verificar se o olho é um "quarto escuro" e se há algo dentro do olho, no caso a retina, que funciona como a parede que coleta a imagem. Da mesma forma, deve-se garantir que o objeto esteja localizado na frente da pupila-perfuração e esteja iluminado.

Pelos aspectos funcionais, a imagem que se coleta na tela aparece invertida, o que gera um problema de explicação da visão, pois o duplo investimento que exige a direção em que vemos os objetos gera dificuldades no modelo e a questão: Como obtemos uma imagem correta do objeto? Isso mostra os limites do modelo analógico. Por outro lado, ao adicionar uma lente na câmera escura, é possível melhorar a nitidez da imagem, o que também geraria correspondência com meios transparentes, como o cristalino e a córnea, que se encontram no olho.

Também podemos perceber a influência de outros grupos sociais como os artistas no trabalho de Kepler, pois para ele o que vemos é uma pintura, ou seja:

A noção de "pintura" kepleriana como expressão da imagem formada na retina relaciona-se analogamente com as técnicas de perspectiva dos pintores renascentistas. Para estes, uma pintura é a representação do que o artista vê, respeitando a distância em que este está de um tema e o local para o qual se dirige a visão do artista ("ponto de vista" e "ponto de fuga", respectivamente; cf. TOSSATO, 2005).

Por último, a história da óptica é extensa e cheia de detalhes que nos mostram como a ciência se desenvolve por meio de controvérsias, da comunicação entre cientistas e da necessidade de explicar, prever e criar fenômenos e sua correspondência com os modelos sempre contingentes. Longe de pretender ser exaustivo na apresentação dos modelos, o que se evidencia é a demarcação dos fenómenos e a estabilização dos factos que dão origem a um modelo teórico. Isso exigiu, como dissemos no início, ter um pé na teoria e outro no mundo real, que é de onde se extraem a maior parte 
dos fenômenos que na Grécia antiga e na Idade Média deram origem a importantes explorações sobre a luz, a refração e a cor. Por outro lado, o desenvolvimento de dispositivos ópticos para melhorar a visão, utilizando analogias com a natureza e o corpo humano, gerou uma série de novos fenômenos que tiveram que ser classificados e compreendidos. Assim, pode-se pensar que um ensino de óptica precisa focar nas interações entre visão e luz, reconhecendo a riqueza de fenômenos e problematizações que em sala de aula mostrem uma imagem da ciência dinâmica e humana.

\section{Agradecimentos}

Os autores agradecem a leitura e revisão crítica realizada pela Ma. Jéssica dos Reis Belíssimo.

\section{Reconstructing some models about light and view from the History of Science}

\section{Abstract}

Throughout history there have been woven conceptions about light and vision that are evident in fields as diverse as physics, theology, psychology, biology, among others. This has implied the development of technologies with diverse applications, while at the same time new understandings have been reached and other phenomena have emerged. The fundamental objective of this article is to take a tour through some models of light and vision that have been collected from the history of optics, giving special attention to refraction. Likewise, it brings a brief discussion of technology and its relationship to science by analyzing the role of the camera obscura as an analog to the eye, expanding the understanding of the mechanism of vision and showing a range of applications from fields as diverse as painting. In conclusion, the history of optics is extensive and full of details that show us how science develops through controversies, communication between scientists, and the need to explain, predict, and create phenomena. Far from claiming to be exhaustive in the presentation of models, what is evident is the demarcation of phenomena and the stabilization of facts that give rise to a theoretical model. Finally, some contributions are suggested for teachers from a perspective of the nature of science and technology that can be considered in the classroom.

Keywords: History of optics, vision models, refraction, dark camera, teaching optics.

\section{Nota}

1 Tomado de https://www.fromoldbooks.org/Richter-NotebooksOfLeonardo/section-2/item-70.html e consultado o 20 de julho de 2021. 
ARIZA, Y.; ADÚRIZ BRAVO, A. Qué Son Los Modelos Científicos: introduciendo La Escuela Semanticista En La Didáctica De Las Ciencias Naturales. II Congreso Internaciona y VIII Nacional de Investigación En Educación Pedagogía y Formación Docente, 2012. p. 1134-1150.

ADÚRIZ-BRAVO, A.; MORALES, L. El concepto de modelo en la enseñanza de la Física-consideraciones epistemológicas, didácticas y retóricas. Caderno Brasileiro de Ensino de Física, v. 19 , n. 1 , p. $79-91,2002$.

AUTHIER, M. La refracción y el olvido cartesiano. In: SERRES, M. (Coord.) Historia de las Ciencias. Cátedra. 1991. p. 287-312.

BRAVO, B.; PESA, M.; POZO, J. I. Los modelos de la ciencia para explicar la visión y el color: las complejidades asociadas a su aprendizaje. Enseñanza de las Ciencias: revista de investigación y experiencias didácticas, v. 28, n. 1, p. 113-126, 2010.

CARDONA, C. A. Leonardo Da Vinci y la compración ojo-cámara obscura. Ideas y Valores, v. 69 , n. 174 , p. $143-171,2020$.

CERQUERA, M. Y.; GARCÍA, E. G. Estudios histórico-críticos sobre la óptica. Implicaciones pedagógicas, p. 1-15, 2016.

DA CRUZ SILVA, B. V.; MARTINS, A. F. P. A natureza da luz e o ensino da óptica: uma experiência didática envolvendo o uso da história e da filosofia da ciência no ensino médio Experiências em Ensino de Ciências, v. 5, n. 2, p. 71-91, 2010.

DE DANON, M. P.; CUDMANI, L. Paralelismo entre los modelos precientíficos e históricos en la óptica-implicancias para la educación. Caderno Brasileiro de Ensino de Física, v. 10, n. 2, p. 128-136, 1993.

EUCLIDES. Óptica. Scientiae Studia, v. 11, n. 4, p. 893-936, 2013. Disponivel em: https://doi. org/10.1590/S1678-31662013000400008.

FLECK, L.; SCHÄFER, L.; SCHNELLE, T.; MEANA, L. La génesis y el desarrollo de un hecho científico: introducción a la teoría del estilo de pensamiento y del colectivo de pensamiento. Madrid: Alianza. 1986.

FRAGA, F. The obscure origins of the camera obscura: Alhacen and his predecesors. EGA Revista de Expresion Grafica Arquitectonica, v. 21, n. 28, p. 82-91, 2016. Disponível em: https://doi. org/10.4995/ega.2016.6050

GAGLIARDI, M.; GIORDANO, E.; RECCHI, M. Un sitio web para la aproximación fenomenológica de la enseñanza de la luz y la visión. Enseñanza de las Ciencias, v. 24, n. 1, p. 139-146, 2006.

GONZÁLEZ-CANO, A. Ibn al-haytham: an optical revolution. Arbor-Ciencia Pensamiento y Cultura. (775), 2015.

HERNÁNDEZ SILVA, C.; IZQUIERDO AYMERICH, M. Formaciones semióticas en libros de texto: uso de modelos para interpretar fenómenos ondulatorios. Enseñanza de las Ciencias, v, extra, p. 3881-3888, 2017.

RODRIGUES NETO, G. Euclides e a geometria do raio visual. Scientiae Studia, v. 11, n. 4, p. 873-892, 2013. Disponivel em: https://doi.org/10.1590/S1678-31662013000400007. 
NEWTON, I.; SOLÍS, C. Optica o tratado de las reflexiones refracciones inflexiones y colores de la luz/sir Isaac Newton: introducción, traducción, notas e índice analítico. Carlos Solís. 1977.

SOLBES MATARREDONA, J. Indagación sobre la visión. Colección Aulas de Verano. Serie Ciencias. Ministerio de educación secretaría de estado de educación y formación profesional. Instituto de Formación del Profesorado, Investigación e Innovación Educativa (IFIIE). 2011.

STEADMAN, P. Vermeer y la cámara oscura, 2011. Disponível em: http://www.arauco.org/ sapereaude/print/vermerylacamaraoscura.pdf

TOSSATO, C. R. Os fundamentos da óptica geométrica de Johannes Kepler. Scientiae Studia, v. 5, p. 471-499, 2007. Disponível em: https://doi.org/10.1590/S1678-31662007000400003. 